\title{
Anti-aggregation therapy in patients with acute coronary syndrome - recommendations for medical emergency teams. Experts' standpoint
}

\author{
Leczenie antyagregacyjne u pacjentów z ostrym zespołem wieńcowym \\ — zalecenia dla zespołów ratownictwa medycznego. Stanowisko ekspertów
}

\begin{abstract}
Jacek Kubica' ${ }^{1}$, Piotr Adamski ${ }^{1}$, Przemysław Paciorek ${ }^{1,2}$, Jerzy R. Ładny ${ }^{3}$, Zbigniew Kalarus ${ }^{4}$, Waldemar Banasiak ${ }^{5}$, Wacław Kochman ${ }^{6}$, Jarosław Gorący ${ }^{7}$, Beata Wożakowska-Kapłon ${ }^{8}$, Eliano Pio Navarese ${ }^{1}$, Andrzej Kleinrok ${ }^{9}$, Robert Gil ${ }^{10}$, Maciej Lesiak ${ }^{11}$, Jarosław Drożdż ${ }^{12}$, Aldona Kubica ${ }^{1}$, Krzysztof J. Filipiak ${ }^{13}$, Jarosław Kaźmierczak ${ }^{7}$, Aleksander Goch ${ }^{1}$, Stefan Grajek ${ }^{11}$, Andrzej Basiński ${ }^{6}$, Łukasz Szarpak ${ }^{13}$, Grzegorz Grześk ${ }^{1}$, Piotr Hoffman ${ }^{14}$, Wojciech Wojakowski ${ }^{4}$, Zbigniew Gąsior ${ }^{4}$, Sławomir Dobrzycki ${ }^{3}$, Jolanta M. Siller-Matula ${ }^{15}$, Adam Witkowski ${ }^{14}$, Wiktor Kuliczkowski ${ }^{16}$, Marcin Gruchała ${ }^{6}$, Dariusz Timler ${ }^{12}$, Grzegorz Opolski ${ }^{13}$, Dariusz Dudek ${ }^{17}$, Jacek Legutko ${ }^{17}$, Marzenna Zielińska ${ }^{12}$, Jarosław Wójcik ${ }^{18}$

'Nicolaus Copernicus University, Collegium Medicum, Bydgoszcz, Poland; 2Regional Emergency Ambulance Service, Bydgoszcz, Poland; ${ }^{3}$ Medical University, Bialystok, Poland; ${ }^{4}$ Silesian Medical University, Zabrze, Poland; ${ }^{5} 4^{\text {th }}$ Military Hospital, Wroclaw, Poland; ${ }^{6}$ Medical University of Gdansk, Poland; ${ }^{7}$ Pomeranian Medical University, Szczecin, Poland; ${ }^{8}$ Jan Kochanowski University, Kielce, Poland; ${ }^{9}$ Regional Hospital, Zamosc, Poland; ${ }^{10}$ Mossakowski Medical Research Centre, Polish Academy of Sciences, Warsaw, Poland;

${ }^{11}$ Poznan University of Medical Science, Poznan, Poland; ${ }^{12}$ Medical University of Lodz, Poland; ${ }^{13}$ Medical University of Warsaw, Poland; ${ }^{14}$ Cardinal Stefan Wyszynski Institute of Cardiology, Warsaw, Poland; ${ }^{15}$ Medical University of Vienna, Austria; ${ }^{16}$ Wroclaw Medical University, Wroclaw, Poland; ${ }^{17}$ Collegium Medicum, Jagiellonian University, Krakow, Poland; ${ }^{18}$ Medical University of Lublin, Poland
\end{abstract}

Reviewer/Recenzent:

Prof. dr hab. n. med. Andrzej Budaj (Polish Cardiac Society/Polskie Towarzystwo Kardiologiczne)

\section{INTRODUCTION}

Cardiovascular diseases (CVD) constitute the most common cause of death globally, and account for 17.5 million deaths annually, or $31 \%$ of all deaths reported worldwide per year [1]. In Europe, more than 4 million patients die due to CVD per year, which is as much as $45 \%$ of all deaths reported annually in the Old Continent [2]. Among all CVD the most common cause of death is ischaemic heart disease (IHD), responsible for about $20 \%$ of all deaths reported in Europe. In Poland, the mortality rate for IHD is currently 191 deaths per 100,000 inhabitants. Noteworthy is the fact that this rate has decreased by $39 \%$ over the last 10 years. Still, however, this rate is markedly lower when calculated for the entire European Union and equals to 132 deaths per 100,000 inhabitants, in some countries being even lower than 100 (France, Portugal, the Netherlands, Spain, Belgium, Denmark, Luxembourg, Greece, and Liechtenstein) [2]. In spite of the improvement in prognosis for patients with acute coronary syndrome (ACS), particularly with myocardial infarction (MI), observed in re- cent years, this form of IHD is still associated with high risk of death. In our country the total in-hospital mortality rate among patients with $\mathrm{MI}$ is about $11 \%$ (6\% for patients managed invasively vs. $18-24 \%$ for patients receiving conservative treatment), while the mortality rate in the first 12 months after $\mathrm{Ml}$ is up to $19 \%$ [3]. It should be noted that despite the major reduction in the in-hospital mortality rate, pre-hospital mortality remains relatively high.

Due to different management strategies applied in patients with ACS, MI is commonly classified as ST-elevation MI (STEMI) or non-ST-elevation ACS (NSTE-ACS). Of note, the epidemiology of ACS in Poland over the recent years has displayed some steady trends of changes. In 2009, 59\% of all patients with MI were those with STEMI, while in 2012 this rate decreased to $48 \%$ [3]. In 2014, patients with STEMI accounted for $33 \%$ of all ACS patients treated with percutaneous coronary intervention (PCI), while patients with non-STEMI (NSTEMI) and unstable angina (UA) accounted for $28 \%$ and $39 \%$, respectively [4]. 
Activation and aggregation of platelets play a key role in the pathophysiology of ACS, including MI [5, 6]. Injury of an atherosclerotic plaque results in intraluminal exposure of elements of the extracellular matrix, such as collagen, von Willebrand factor, fibronectin, or laminin. Contact of the platelets with these molecules triggers platelet activation, which starts the cascade of events leading to thrombus formation [7-10]. Activated platelets release active substances stored in their dense granularities, i.a. adenosine diphosphate (ADP), which is the main agonist of the platelet P2Y12 receptor $[11,12]$.

Activation of the platelet $\mathrm{P} 2 \mathrm{Y} 12$ receptor by ADP plays a pivotal role in sustaining platelet activation and stabilisation of platelet aggregates. These processes lead to formation of a platelet-rich thrombus at the site of damage of the wall of a coronary artery, with resulting impairment of coronary blood flow and reduced oxygen supply to cardiomyocytes [13]. The most common clinical manifestation of myocardial ischaemia is ACS-specific chest pain. Other possible clinical presentations of ACS include i.a.: dyspnoea, abdominal pain, nausea/vomiting, general weakness, loss of consciousness, or sudden cardiac death. Prolonged myocardial ischaemia ultimately results in necrosis of myocardial cells and development of MI [5]. The multidimensional impact of P2Y12 receptor activation on the processes associated with formation of thrombi within the lumen of coronary arteries is the reason why this receptor has become one of the main targets of antiplatelet therapy.

\section{ANTI-AGGREGATION TREATMENT IN PATIENTS WITH ACS IN POLAND}

Nowadays the role of medical emergency team members is not only to quickly establish the preliminary diagnosis or to secure efficient transport of an ACS patient to hospital, but also, equally importantly, to initiate the treatment of ACS patients, particularly by starting antiplatelet therapy.

Restriction of excess platelet activation and inhibition of platelet aggregation with dual antiplatelet therapy (DAPT), including acetylsalicylic acid (ASA) and one of the P2Y12 receptor inhibitors, is already a standard of care in patients with ACS [14-16].

There are recommendations, developed by experts commissioned by international scientific societies, addressing optimal therapeutic management strategies for patients with ACS, including the strategy for use of DAPT. Continuous progress in medical knowledge, and the specific situation in our country with respect to drug availability and organisation of the system of medical emergency service and hospital care, warrant presentation of a standpoint concerning the clinical practice used to date.

The principles of the antiplatelet therapy currently used in Poland in ACS patients are based on the following three documents: the guidelines of the European Society of Cardiology (ESC) on the management of STEMI published in 2012; guide- lines of the ESC and European Association for Cardio-Thoracic Surgery (EACTS) on myocardial revascularisation published in 2014; and guidelines of the ESC on management of NSTE-ACS published in 2015 [14-16]. The guidelines of ESC concerning use of DAPT in patients with ACS were confirmed, although much less precisely, in the guidelines of the European Resuscitation Council (ERC) published in 2015 [17].

\section{ACETYLSALICYLIC ACID THERAPY IN PATIENTS WITH ACS}

Acetylsalicylic acid is an irreversible inhibitor of platelet cyclooxygenase isoenzyme type 1 (COX-1). According to the current guidelines, administration of an oral, rapidly absorbed ASA formulation in a loading dose of 150-300 mg is recommended in all ACS patients with no contraindications and no history of prior chronic use of ASA. When oral intake is not possible, ASA can be administered intravenously in the dose of 75-150 mg, however the i.v. formulation of ASA is not available in Poland. Quite often ASA is administered in the pre-hospital period. According to the current guidelines, in patients with STEMI, treatment should be applied as early as possible, i.e. upon the first medical contact. Then, all patients should receive chronic therapy with ASA 75-100 mg q.d. - class of recommendation I, level of evidence A [14-16]. Increasing the dose above that level not only does not improve treatment efficacy, but also increases the risk of bleeding [18-20].

\section{PLATELET P2Y12 RECEPTOR INHIBITORS}

The current recommendations concerning the treatment of patients with ACS emphasise the need to use DAPT, including ASA and a platelet P2Y12 receptor inhibitor, for 12 months following ACS, unless contraindicated due to excessive risk of bleeding - class of recommendation I, level of evidence A. This recommendation is valid for patients both with STEMI and NSTE-ACS $[15,16]$.

Currently, the oral platelet P2Y12 inhibitors available in Poland are: clopidogrel, prasugrel, and ticagrelor. A registered, but still unavailable medication of this group is cangrelor - a compound designed for intravenous use only. Clopidogrel and prasugrel are pro-drugs and require activation in the liver into active metabolites irreversibly blocking the P2Y12 receptor, whereas ticagrelor and cangrelor are active drugs, which directly and reversibly block this receptor (Table 1) [16].

The guidelines preferentially recommend the newer P2Y12 inhibitors (prasugrel and ticagrelor) for their faster, more potent, and more uniform anti-aggregation effect translating into better clinical outcomes as compared with clopidogrel [21-25].

A clinical study entitled Trial to Assess Improvement in Therapeutic Outcomes by Optimising Platelet Inhibition with Prasugrel-Thrombolysis in Myocardial Infarction 38 (TRITON-TIMI 38) demonstrated superiority of prasugrel over clopidogrel for reduction of composite ischaemic end- 
Table 1. Comparison of P2Y12 receptor inhibitors recommended by the European Society of Cardiology

\begin{tabular}{|c|c|c|c|c|}
\hline & clopidogrel & prasugrel & ticagrelor & cangrelor \\
\hline Chemical class & Thienopyridine & Thienopyridine & $\begin{array}{l}\text { Cyclopentyl-triazolo- } \\
\text {-pyrimidine }\end{array}$ & ATP analogue \\
\hline Administration route & Oral & Oral & Oral & Intravenous \\
\hline \multicolumn{5}{|l|}{ Standard dosing: } \\
\hline Loading dose & 300 or 600 mg & $60 \mathrm{mg}$ & $180 \mathrm{mg}$ & $30 \mu \mathrm{g} / \mathrm{kg}$ bolus \\
\hline Maintenance dose & $\begin{array}{l}1 \times 75 \mathrm{mg} \mathrm{or} \\
1 \times 150 \mathrm{mg}\end{array}$ & $\begin{array}{l}1 \times 10 \mathrm{mg} \text { or } \\
1 \times 5 \mathrm{mg}\end{array}$ & $2 \times 90 \mathrm{mg}$ & $\begin{array}{l}4 \mu \mathrm{g} / \mathrm{kg} / \mathrm{min} \\
\text { infusion }\end{array}$ \\
\hline Prodrug & Yes & Yes & No & No \\
\hline P2Y12 receptor binding & Irreversible & Irreversible & Reversible & Reversible \\
\hline Onset of antiplatelet effect & $2-6 \mathrm{~h} \#$ & $30 \min \#$ & $30 \mathrm{~min} \#$ & $2 \min$ \\
\hline Offset of antiplatelet effect & $3-10$ days & 5-10 days & 3-4 days & $1-2 h$ \\
\hline Recommended withdrawal before surgery & 5 days & 7 days & 5 days & $1 \mathrm{~h}$ \\
\hline
\end{tabular}

\#Data from healthy volunteers and patients with stable coronary disease. In patients with acute coronary syndromes the onset of action is probably delayed; ATP — adenosine triphosphate

Table 2. Contraindications to use of oral P2Y12 receptor antagonists

\begin{tabular}{|l|l|}
\hline Contraindication & clopidogrel \\
\hline Active bleeding & \\
\hline Severe liver disorders & Within 7 days \\
\hline History of ischaemic stroke & \\
\hline History of $\mathrm{TIA}$ & \\
\hline History of intracranial haemorrhage & \\
\hline Age $\geq 75$ years & \\
\hline Body weight $<60 \mathrm{~kg}$ & \\
\hline
\end{tabular}

TIA — transient ischaemic attack; blue — can be used; grey — is not recommended; black — should not be used

point [26]. Repeated ischaemic cardiovascular events were less frequent $(9.3 \%$ vs. $11.2 \%$; $p=0.002)$, whereas severe haemorrhagic complications were more frequent (2.4\% vs. $1.8 \%$; $\mathrm{p}=0.03$ ) in patients treated with prasugrel, as compared with those receiving clopidogrel [26]. Particularly great benefits of treatment with prasugrel, with no increase in bleeding risk, are observed in patients with ACS and diabetes mellitus [27].

Another clinical study, entitled Platelet Inhibition and Patient Outcomes (PLATO), conducted in patients with ACS, demonstrated better outcomes of treatment with ticagrelor vs. clopidogrel with respect to reduction in the rates of composite ischaemic endpoint (9.8\% vs. $11.7 \%$; $\mathrm{p}<0.001)$ and cardiovascular mortality $(4.0 \%$ vs. $5.1 \%$; $p=0.001$ ) [28], with no concomitant increase in the risk of severe bleeding.

When starting treatment with P2Y12 inhibitors one should always be aware of contraindications for these drugs. Prasugrel is contraindicated in patients with a history of intracranial haemorrhage, ischaemic cerebral stroke or transient ischae- mic attacks, or with active bleeding. Prasugrel is generally not recommended for patients above 75 years of age or with body weight below $60 \mathrm{~kg}$. Also, ticagrelor is contraindicated in patients with a history of intracranial haemorrhage or with active bleeding. Moreover, both prasugrel and ticagrelor are not recommended for use in dialysis patients and in those requiring chronic oral anticoagulation (Table 2 ).

It should be emphasised that clopidogrel is the only P2Y12 inhibitor to be used in combination with oral anticoagulants (acenocoumarol, apixaban, dabigatran, rivaroxaban, or warfarin). Use of ticagrelor or prasugrel as part of triple therapy is not recommended - class of recommendation III, level of evidence C [15].

\section{Platelet P2Y12 receptor inhibitors in the treatment of patients with STEMI}

Detection of persistent ST elevation in two neighbouring electrocardiogram (ECG) leads in a patient with stenocardial complaints substantiates the preliminary diagnosis of STEMI. 
STEMI is most commonly caused by total occlusion of a coronary artery, which results in progressive necrosis of myocardial cells. This implies the necessity to restore patency of the occluded artery as soon as possible. The preferred method of coronary revascularisation is $\mathrm{PCl}[14,16]$. The ESC guidelines emphasise that pre-hospital management of patients with STEMI must be based on regional networks designed to secure quick and effective reperfusion therapy. Mobile medical emergency teams must be trained and equipped appropriately to be able to diagnose STEMI (also employing ECG teletransmission systems) and initiate early treatment, if indicated [14].

In STEMI patients it is recommended to administer a P2Y12 inhibitor at first contact with the healthcare system — class of recommendation I, level of evidence B [16]. Although this approach appears to be justified, currently there are no randomised clinical trials demonstrating clear clinical benefits of this treatment strategy [29]. Simultaneously, administration of oral P2Y12 inhibitors in pre-hospital management of patients with STEMI is considered to be safe [29].

For patients with STEMI the preferred P2Y12 inhibitors are prasugrel (administered at an initial loading dose of $60 \mathrm{mg}$, unless contraindicated, and at a maintenance dose of $10 \mathrm{mg}$ q.d.) and ticagrelor (at an initial loading dose of $180 \mathrm{mg}$, unless contraindicated, and at a maintenance dose of $90 \mathrm{mg}$ b.i.d.) - both equally recommended for patients with STEMI - class of recommendation I, level of evidence B [14, 16]. As mentioned earlier, when prasugrel or ticagrelor are unavailable or contraindicated, a loading dose of clopidogrel (600 mg) should be administered [14, 16]. It should be noted that patients who have already received a loading dose of clopidogrel may have their antiplatelet therapy modified and ticagrelor can be administered [28], which is not recommended for prasugrel.

Based on theoretical evidence derived from pharmacokinetic and pharmacodynamic properties as well as on the results of clinical studies, cangrelor appears to be the optimal P2Y12 inhibitor for ACS patients requiring urgent invasive treatment. Unfortunately, this compound is still commercially unavailable [30, 31]. Moreover, studies to evaluate the efficacy and safety of cangrelor in the pre-hospital management period have not been conducted to date. Cangrelor may potentially be of particular benefit in unconscious patients, patients with post-cardiac arrest syndrome, or patients treated with mild therapeutic hypothermia, when gastrointestinal absorption of medications is impaired [32, 33].

In accordance with the ESC guidelines, it is a common practice in our country to initiate antiplatelet therapy in patients suspected of STEMI as early as at the stage of pre-hospital management, in the ambulance, after verification of the initial diagnosis by a cardiologist based on teletransmission of the patient's ECG. Patients receiving antiplatelet therapy in this period usually receive a loading dose of clopidogrel, rather than prasugrel or ticagrelor. According to the current guidelines, this treatment strategy is not optimal; however, it is acceptable when prasugrel or ticagrelor are unavailable or contraindicated.

\section{Platelet P2Y12 receptor inhibitors in the treatment of patients with NSTE-ACS}

The clinical forms of NSTE-ACS include NSTEMI and UA. In patients with NSTEMI necrosis of cardiomyocytes develops secondary to myocardial ischaemia, whereas in the case of UA myocardial ischaemia occurs without resulting loss of cardiac muscle cells. Differential diagnosis between NSTEMI and UA is based on measurements of the levels of myocardial necrosis markers, mainly troponin I or T [15].

While possibly quick initiation of antiplatelet therapy and urgent coronary reperfusion are recommended for patients with STEMI, in patients with NSTE-ACS the indications and recommended timeframes for diagnostics and potential invasive treatment depend primarily on risk stratification based on the patient's clinical history, leading signs and symptoms, vital parameters, other signs and symptoms, as well as results of ECG and laboratory tests. Therefore, only some patients with NSTE-ACS (very high risk patients) require urgent (within $2 \mathrm{~h}$ ) coronary angiography and usually $\mathrm{PCl}$. The urgent approach is indicated in the presence of at least one of the following factors:

- unstable haemodynamic condition or cardiogenic shock;

- recurrent or sustained chest pain resistant to conservative treatment;

- life-threatening cardiac arrhythmia or cardiac arrest;

- mechanical complications of ACS:

- acute heart failure;

- recurrent dynamic changes of ST-T segment, especially with transient ST elevation [15].

Similar to STEMI, a 12-month course of DAPT, including ASA and one of the P2Y12 inhibitors, is also recommended in patients with NSTE-ACS, unless contraindicated, e.g. due to excessive risk of bleeding [15]. The guidelines concerning treatment of NSTE-ACS contain information that therapy with P2Y12 inhibitors should be instituted immediately after establishing the diagnosis of NSTE-ACS, regardless of the management strategy. Unfortunately, that document does not provide more precise recommendations concerning the optimal time of initiation of antiplatelet therapy in such patients. In this group of patients the preferred $\mathrm{P} 2 \mathrm{Y} 12$ inhibitors are prasugrel and ticagrelor, with equal recommendations - class of recommendation I, level of evidence B [15].

For NSTE-ACS prasugrel is recommended in patients qualified for $\mathrm{PCl}$. Simultaneously, its early administration is discouraged in patients with unknown anatomy of the coronary arteries - class of recommendation III, level of evidence $B$ [15]. Respecting both of these recommendations means that patients with NSTE-ACS should not be given prasugrel prior 
to coronary angiography or when qualified for conservative treatment. In practice, these limitations preclude pre-hospital use of prasugrel in NSTE-ACS patients.

For NSTE-ACS, a ticagrelor loading dose of $180 \mathrm{mg}$ followed by $90 \mathrm{mg}$ b.i.d. is recommended in all patients with moderate and high risk of ischaemic events, regardless of the initial management strategy, unless contraindicated. It is important to note that this recommendation also includes patients who had received clopidogrel previously (in case of which clopidogrel should be discontinued at the time of initiation of ticagrelor treatment). This means that ticagrelor can be used also in those NSTE-ACS patients who are not candidates for prasugrel, i.e. in patients on conservative treatment, prior to coronary angiography, and in those who had received a loading dose of clopidogrel [15].

A clopidogrel loading dose of 300-600 mg followed by $75 \mathrm{mg}$ q.d. is recommended in patients with NSTE-ACS, who cannot receive ticagrelor and prasugrel or require oral anticoagulant therapy — class of recommendation I, level of evidence B [15].

\section{ANALGETIC TREATMENT}

Morphine is the primary analgetic drug used in patients with ACS, particularly in those with MI. In addition to potent analgetic action, this opioid also has tranquillising and euphoric effects. Effective reduction of the severity of chest pain and sedation of the patient result in a decrease of arterial blood pressure and heart rate, which improves myocardial oxygen demand/delivery ratio [34]. Due to its potential positive effect on the pathophysiology of ACS, high efficacy in symptomatic management of chest pain, wide availability, and long-term experience of clinical use, morphine is commonly used in ACS patients. Morphine is frequently administered in patients with ACS already at the pre-hospital stage, with the intention to reduce pain during transport to hospital before causative therapy is initiated.

However, use of morphine quite commonly produces adverse effects, such as bradycardia, arterial hypotension, and impairment of the intestinal propulsive function, and sometimes also suppression of respiratory function [35]. The influence of morphine on the gastrointestinal tract and central nervous system may lead to vomiting and deceleration of intestinal transit, which may result in impaired and delayed absorption of oral medications, including DAPT [35]. In the event of respiratory depression following morphine administration, this effect may be reverted with intravenous naloxone (usually a single dose of $0.4-2 \mathrm{mg}$, repeated doses every 2-3 $\mathrm{min}$, if needed) [36].

Currently there are no randomised clinical studies to evaluate the safety of morphine in patients with ACS, and the data from registries are equivocal [37-39]. However, results of numerous clinical tests point to a possible negative effect of morphine on the extent of infarction, patient mortality rate, and absorption and efficacy of oral P2Y12 inhibitors [38, 40-45].

As there is no effective alternative to morphine in analgetic management of patients with ACS, this drug has been reappearing in subsequent editions of ESC guidelines. In patients with STEMI with pronounced-to-severe chest pain graded intravenous dosing of morphine is recommended for reduction of pain complaints - class of recommendation I, level of evidence C [14]. The most recent guidelines concerning the management of NSTE-ACS provide no official recommendation for the use of morphine in that group of patients. The authors confirm, however, that administration of opioids is reasonable when the patient is waiting for urgent coronary angiography, with morphine or alternative opioids reserved for patients with sustained severe chest pain [15]. It should be noted that these recommendations are not based on the results of randomised clinical trials, but on experts' opinion only.

Considering the current knowledge, routine withdrawal from morphine use in ACS patients cannot be recommended. It seems reasonable, however, to reserve this treatment only for those patients who report severe chest pain or present with signs of acute heart failure (e.g. resting dyspnoea) [46]. It also appears justified to use the minimal effective dose with a view to limit the adverse effects of morphine.

\section{COMMENT}

It should be emphemphasised that clopidogrel, which is still commonly used in our country, according to current guidelines is not the first-choice P2Y12 inhibitor in patients with ACS any more. For these patients, ESC guidelines clearly recommend use of ticagrelor or prasugrel as preferred P2Y12 blockers. Contrary to prasugrel, ticagrelor is recommended for all patients with STEMI and NSTE-ACS, regardless of management strategy, including patients on conservative treatment and those who had already received clopidogrel previously. Prasugrel, in turn, is recommended in patients with STEMI, and exclusively in NSTE-ACS patients who have been qualified for $\mathrm{PCl}$ based on the results of coronary angiography. According to current ESC guidelines, use of clopidogrel in patients with STEMI or NSTE-ACS should be limited to situations when both ticagrelor and prasugrel are unavailable or contraindicated — class of recommendation I, level of evidence B [15, 16].

We should remember, however, about a distinctive group of ACS patients who otherwise require anticoagulant therapy, e.g. due to atrial fibrillation, since they should be treated with clopidogrel rather than prasugrel or ticagrelor. Therefore, it is very important to correctly assess the patient for the presence of potential contraindications prior to initiation of treatment with an oral P2Y12 inhibitor.

Another important subgroup of ACS patients are those who - following diagnostic coronary angiography — become candidates for urgent coronary artery bypass grafting 
(CABG). In Poland $2 \%$ of all patients with MI undergo CABG during hospitalisation due to ACS [3]. Identification of patients requiring $\mathrm{CABG}$ is based on the results of imaging of the coronary arteries (coronary angiography) and therefore is not possible in the pre-hospital period. However, the fact that some patients may require urgent cardiac surgery shortly after establishing the diagnosis of ACS by the medical emergency team should somehow affect and define the pre-hospital management strategy in these cases. Wherever possible, direct transport of the highest risk patients (STEMI and NSTE-ACS of very high risk) to centres with both invasive cardiology and cardiac surgery facilities should be considered. It should be stressed, however, that the preference for this category of hospitals must not cause delay of invasive diagnostics. Long-term outcomes of treatment of patients with ACS undergoing urgent CABG are also affected by the applied antiplatelet therapy. In ACS patients treated with $C A B G$, ticagrelor therapy results in reduction of risk of adverse cardiovascular events, including death rates, as compared with clopidogrel, without increasing the risk of severe CABG-related bleeding [47]. In comparison with clopidogrel, prasugrel, the other of the two P2Y12 inhibitors preferred in patients with ACS, increases the risk of CABG-related bleeding [26]. Therefore, when initiating antiplatelet therapy in the pre-hospital setting, it seems justified to prefer ticagrelor as the first-choice drug in patients who may potentially require urgent cardiac surgery.

The choice of the optimal time to start therapy with oral antiplatelet drugs is not supported by the results of the available clinical studies. Except for the results of two studies: Targeted Platelet Inhibition to Clarify the Optimal Strategy to Medically Manage Acute Coronary Syndromes (TRILOGY-ACS) and A Comparison of Prasugrel at $\mathrm{PCl}$ or Time of Diagnosis of Non-ST Elevation Myocardial Infarction (ACCOAST), which indicate lack of justification for use of prasugrel in patients with NSTE-ACS on conservative treatment and prior to coronary angiography, there are no data from randomised studies defining the optimal time point for initiation of treatment with P2Y12 inhibitors in NSTE-ACS patients $[48,49]$. Hence, it is difficult to formulate universal recommendations concerning early administration of ticagrelor or clopidogrel for all NSTE-ACS patients [15, 50]. Still, however, for patients of very high risk, who require urgent invasive diagnostics and most commonly also $\mathrm{PCl}$, it seems advisable to institute DAPT as soon as possible.

The data concerning the optimal period for initiation of antiplatelet therapy in patients with STEMI are not fully consistent, either. A randomised clinical study Administration of Ticagrelor in the Cath Lab or in the Ambulance for New ST Elevation Myocardial Infarction to Open the Coronary Artery (ATLANTIC) was conducted to evaluate the influence of administration of a loading dose of ticagrelor during transport to hospital versus at the catheterisation lab, on cardiac reperfusion in 1862 patients with STEMI. No improvement in cardiac reperfusion before $\mathrm{PCl}$ was found in those study participants who received a pre-hospital loading dose of ticagrelor. Importantly, no increase in the number of hemorrhagic complications was observed in that group. The lack of benefits otherwise expected in association with earlier administration of a loading dose of ticagrelor was suggested to result from a relatively small time difference of 31 min between its pre-hospital vs. in-hospital administration [51]. The fact that as many as $50 \%$ of the study participants received morphine is also likely to be responsible for the final effect. An additional analysis of the ATLANTIC study demonstrated that administration of a loading dose of ticagrelor in the pre-hospital setting in combination with $\mathrm{PCl}$ was associated with a lower incidence of ischaemic events within the first $24 \mathrm{~h}$ of treatment, as compared with in-hospital administration of ticagrelor followed by PCI [52]. The results of the ATLANTIC study confirmed safety of ticagrelor administration in the pre-hospital setting in STEMI patients and provided a potent suggestion of clinical benefits associated with this management strategy. These results seem to warrant the earliest possible administration of a loading dose of ticagrelor by medical emergency teams when STEMI is diagnosed and no contraindications exist.

\section{SUMMARY}

1. Use of ECG teletransmission and teleconsultation systems should be part of standard management in all patients with suspected ACS [53]. Utilisation of the consultation options facilitates quick diagnosis of STEMI and NSTE-ACS, which enables early initiation of DAPT in all the patients who require this treatment. It also makes logistic management more efficient and decreases the time delay to revascularisation.

2. In order to make the therapeutic management of STEMI patients uniform, after preliminary diagnosis and teleconsultation with a cardiologist, if no contraindications exist, an oral loading dose of one of the P2Y12 receptor inhibitors should be administered; patients with no record of previous intake of ASA should also be given a $300 \mathrm{mg}$ loading dose of ASA. Due to the potential need for cardiac surgical treatment, it is advisable in some patients to choose ticagrelor in a loading dose of $180 \mathrm{mg}$ (Fig. 1).

3. Routine pre-hospital initiation of treatment with platelet P2Y12 receptor inhibitors in all patients with NSTE-ACS is not recommended. However, early initiation of antiplatelet therapy appears advisable in patients with NSTE-ACS of very high risk, for whom preliminary assessment indicates the need for urgent invasive treatment. In such cases patients with no record of previous ASA intake should be administered a $300 \mathrm{mg}$ loading dose of ASA and a $180 \mathrm{mg}$ loading dose of ticagrelor; when ticagrelor is unavailable or contraindicated, $300 \mathrm{mg}$ or $600 \mathrm{mg}$ clopidogrel should be given instead (Fig. 1). It 


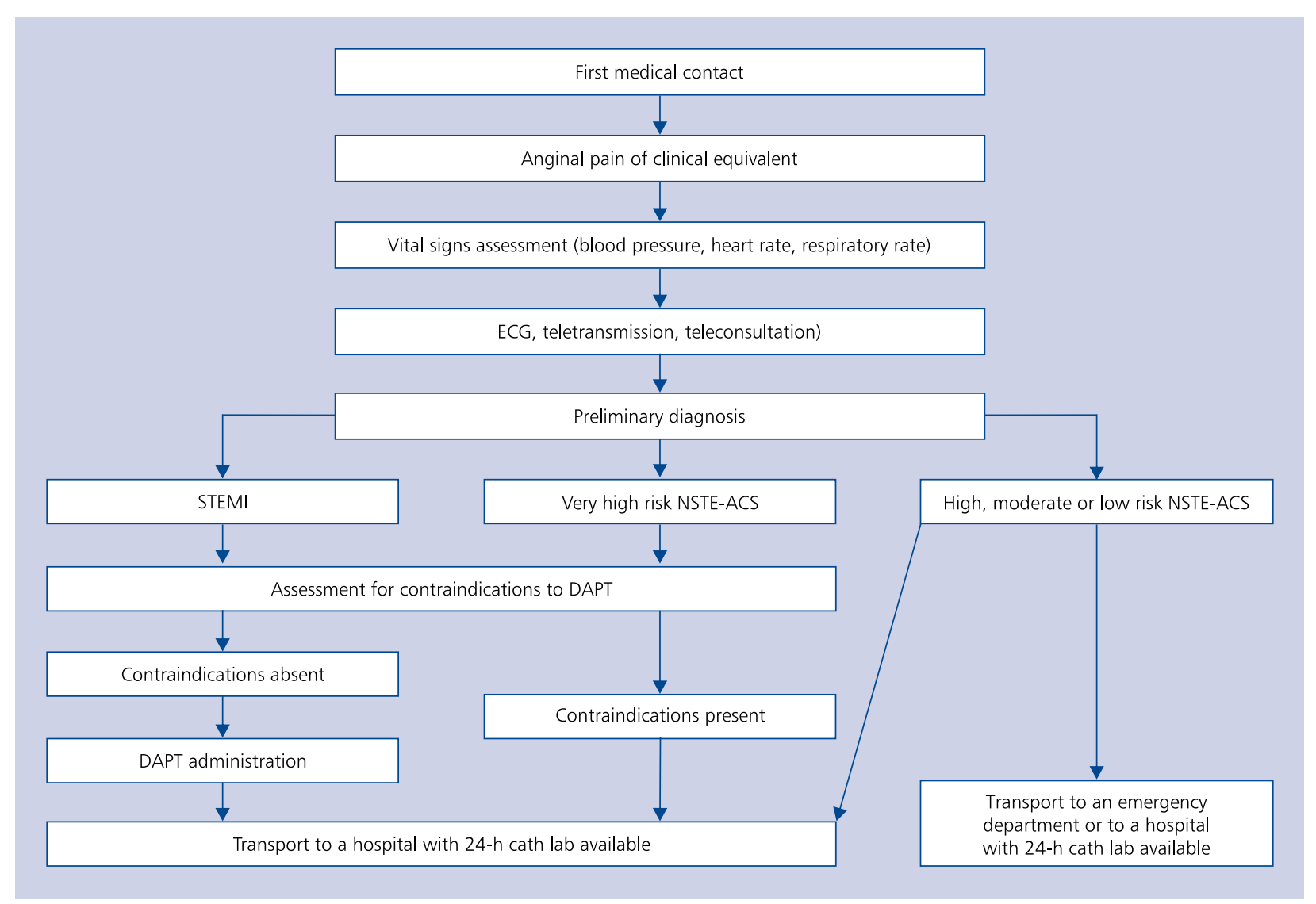

Figure 1. Algorithm for pre-hospital management of patients with acute coronary syndromes; DAPT — dual antiplatelet therapy: preferred treatment: aspirin + ticagrelor (considering contraindications); ECG — electrocardiography; NSTE-ACS — non-ST elevation acute coronary syndrome; STEMI — ST-elevation myocardial infarction

should also be noted that, in accordance with the Directive of the Minister of Health dated 20 April 2016, paramedics/emergency medical team members are allowed to (after ECG teletransmission and consultation with the physician evaluating the ECG) administer some P2Y12 inhibitors, namely clopidogrel and ticagrelor, but not prasugrel. In the periprocedural period STEMI patients require antithrombotic treatment apart from DAPT, and, according to the above-mentioned Directive of the Minister of Health, unfractionated heparin $(70-100 \mathrm{U} / \mathrm{kg})$ is the only antithrombotic agent that can be administered by paramedics/emergency medical team members [54].

4. Considering the lack of consistent data, analgetic treatment applied in patients with ACS during their transfer to hospital should be chosen and adjusted on an individual basis. Use of non-opioid drugs is not recommended in such conditions due to increased risk of bleeding when used simultaneously with DAPT [55]. Due to potential interactions with oral antiplatelet drugs, care must be taken when morphine and perhaps also other opioids are used [35]. However, analgetic treatment definitely cannot be denied to suffering patients, who experience high-intensity chest pain or dyspnoea. In such cases it appears reasonable to use the minimum effective dose. Also, when morphine is used, administration of oral antiplatelet drugs in crushed form may be considered, as it was demonstrated that crushing the tablets accelerates their absorption from the gastrointestinal tract and shortens the time to onset of action [56-58].

5. In the pre-hospital period patients with ACS may experience vomiting with risk of loss of the yet unabsorbed antiplatelet drugs. In such cases the time elapsed from drug intake to vomiting and the potential presence of tablets in the vomited content should be documented. The decision on administration of an additional dose of antiplatelet drugs should be left to the discretion of the physician at the destination hospital.

This document was prepared on the grounds of currently valid guidelines and recommendations, currently available results of clinical studies, and theoretical assumptions, and is a consensus standpoint of the authors on anti-aggregation therapy in patients with ACS in the pre-hospital period. 
Conflict of interest: Jacek Kubica: fee for lectures and involvement in AstraZeneca advisory board; Piotr Adamski: fee for lectures for AstraZeneca; Przemysław Paciorek: none; Jerzy R. Ładny: fee for lectures for AstraZeneca; Zbigniew Kalarus: fee for lectures for Eli Lilly and for involvement in AstraZeneca advisory board; Waldemar Banasiak: fee for lectures for AstraZeneca and Bayer, fee for involvement in AstraZeneca, Bayer, and Eli Lilly advisory boards; Wacław Kochman: none; Jarosław Gorący: fee for lectures for AstraZeneca; Beata Wożakowska-Kapłon: fee for lectures and for involvement in AstraZeneca, Adamed, KRKA, and Sanofi advisory boards; Eliano Pio Navarese: none; Andrzej Kleinrok: none; Robert Gil: none; Maciej Lesiak: fee for lectures for AstraZeneca; Jarosław Drożdż: fee for lectures and involvement in Polpharma advisory board; Aldona Kubica: none; Krzysztof J. Filipiak: fee for lectures and for involvement in AstraZeneca, Adamed, KRKA, Polpharma, and Sanofi advisory boards; Jarosław Kaźmierczak: fee for involvement in AstraZeneca advisory board; Aleksander Goch: none; Stefan Grajek: fee for involvement in AstraZeneca advisory board; Andrzej Basiński: none; Łukasz Szarpak: none; Grzegorz Grześk: none; Piotr Hoffman: none; Wojciech Wojakowski: fee for lectures for AstraZeneca; Zbigniew Gąsior: fee for lectures for Servier, and Actelion; Sławomir Dobrzycki: none; Jolanta M. Siller-Matula: fee for lectures and involvement in AstraZeneca, Daiichi Sankyo, and Eli Lilly advisory boards; Adam Witkowski: none; Wiktor Kuliczkowski: none; Marcin Gruchała: none; Dariusz Timler: none; Grzegorz Opolski: none; Dariusz Dudek: fee for lectures and involvement in AstraZeneca advisory board; Jacek Legutko: fee for lectures and involvement in AstraZeneca advisory board; Marzenna Zielińska: fee for lectures for AstraZeneca; Jarosław Wójcik: none

\section{References}

1. Cardiovascular diseases. http://www.who.int/mediacentre/factsheets/ fs317/en/ (accessed 16.10.2016).

2. Townsend N, Nichols M, Scarborough P, et al. Cardiovascular disease in Europe--epidemiological update 2015. Eur Heart J. 2015; 36(40): 2696-2705, doi: 10.1093/eurheartj/ehv428, indexed in Pubmed: 26306399.

3. Gierlotka M, Zdrojewski T, Wojtyniak B, et al. Incidence, treatment, in-hospital mortality and one-year outcomes of acute myocardial infarction in Poland in 2009-2012--nationwide AMI-PL database. Kardiol Pol. 2015; 73(3): 142-158, doi: 10.5603/KP.a2014.0213, indexed in Pubmed: 25371307.

4. Ochała A, Siudak Z, Legutko J, et al. Percutaneous interventions in cardiology in Poland in the year 2014. Summary report of the Association of Cardiovascular Interventions of the Polish Cardiac Society AISN PTK. Postepy Kardiol Interwencyjnej. 2015; 11(3): 177-181, doi: 10.5114/pwki.2015.54009, indexed in Pubmed: 26677356.

5. Thygesen K, Alpert JS, Jaffe AS, et al. Third universal definition of myocardial infarction. Eur Heart J. 2012; 33(20): 2551-2567, doi: 10.1093/eurhearti/ehs184.

6. Lange RA, Hillis LD. Antiplatelet therapy for ischemic heart disease. N Engl J Med. 2004; 350(3): 277-280, doi: 10.1056/NEJMe038191, indexed in Pubmed: 14724308.

7. Badimon L, Padró T, Vilahur G. Atherosclerosis, platelets and thrombosis in acute ischaemic heart disease.
Eur Heart J Acute Cardiovasc Care. 2012; 1(1): 60-74, doi: 10.1177/2048872612441582, indexed in Pubmed: 24062891.

8. Massberg S, Gawaz M, Grüner S, et al. A crucial role of glycoprotein VI for platelet recruitment to the injured arterial wall in vivo. J Exp Med. 2003; 197(1): 41-49, doi: 10.1084/jem.20020945, indexed in Pubmed: 12515812.

9. Schaff M, Tang C, Maurer E, et al. Integrin $\alpha 6 \beta 1$ is the main receptor for vascular laminins and plays a role in platelet adhesion, activation, and arterial thrombosis. Circulation. 2013; 128(5): 541-552, doi: 10.1161/CIRCULATIONAHA.112.000799, indexed in Pubmed: 23797810.

10. Hou Y, Carrim N, Wang Y, et al. Platelets in hemostasis and thrombosis: Novel mechanisms of fibrinogen-independent platelet aggregation and fibronectin-mediated protein wave of hemostasis. J Biomed Res. 2015 [Epub ahead of print]; 29, doi: 10.7555/JBR.29.20150121, indexed in Pubmed: 26541706.

11. Kuijpers MJE, Schulte V, Bergmeier W, et al. Complementary roles of glycoprotein VI and alpha2beta1 integrin in collagen-induced thrombus formation in flowing whole blood ex vivo. FASEB J. 2003; 17(6): 685-687, doi: 10.1096/fj.02-0381fje, indexed in Pubmed: 12586747.

12. Savi P, Zachayus JL, Delesque-Touchard N, et al. The active metabolite of Clopidogrel disrupts P2Y12 receptor oligomers and partitions them out of lipid rafts. Proc Natl Acad Sci U S A. 2006; 103(29): 11069-11074, doi: 10.1073/pnas.0510446103, indexed in Pubmed: 16835302.

13. Dorsam RT, Kunapuli SP. Central role of the P2Y12 receptor in platelet activation. J Clin Invest. 2004; 113(3): 340-345, doi: 10.1172/JCI20986, indexed in Pubmed: 14755328.

14. Steg PhG, James SK, Atar D, et al. Task Force on the management of ST-segment elevation acute myocardial infarction of the European Society of Cardiology (ESC). ESC Guidelines for the management of acute myocardial infarction in patients presenting with ST-segment elevation. Eur Heart J. 2012; 33(20): 2569-2619, doi: 10.1093/eurheartj/ehs215, indexed in Pubmed: 22922416.

15. Roffi M, Patrono C, Collet JP, et al. Management of Acute Coronary Syndromes in Patients Presenting without Persistent ST-Segment Elevation of the European Society of Cardiology. 2015 ESC Guidelines for the management of acute coronary syndromes in patients presenting without persistent ST-segment elevation: Task Force for the Management of Acute Coronary Syndromes in Patients Presenting without Persistent ST-Segment Elevation of the European Society of Cardiology (ESC). Eur Heart J. 2016; 37(3): 267-315, doi: 10.1093/eurheartj/ehv320, indexed in Pubmed: 26320110.

16. Windecker S, Kolh P, Alfonso F, et al. Authors/Task Force members. 2014 ESC/EACTS Guidelines on myocardial revascularization: The Task Force on Myocardial Revascularization of the European Society of Cardiology (ESC) and the European Association for Cardio-Thoracic Surgery (EACTS)Developed with the special contribution of the European Association of Percutaneous Cardiovascular Interventions (EAPCI). Eur Heart J. 2014; 35(37): 2541-2619, doi: 10.1093/eurheartj/ehu278, indexed in Pubmed: 25173339.

17. Nikolaou NI, Arntz HR, Bellou A, et al. Initial management of acute coronary syndromes section Collaborator. European Resuscitation Council Guidelines for Resuscitation 2015 Section 8. Initial management of acute coronary syndromes. Resuscitation. 2015; 95: 264-277, doi: 10.1016/j. resuscitation.2015.07.030, indexed in Pubmed: 26477416.

18. Patrono C, Andreotti F, Arnesen $\mathrm{H}$, et al. Antiplatelet agents for the treatment and prevention of atherothrombosis. Eur Heart J. 2011; 32(23): 2922-2932, doi: 10.1093/eurheartj/ehr373, indexed in Pubmed: 22019823. 
19. Patrono C, García Rodríguez LA, Landolfi R, et al. Low-dose aspirin for the prevention of atherothrombosis. N Engl J Med. 2005; 353(22): 2373-2383, doi: 10.1056/NEJMra052717, indexed in Pubmed: 16319386.

20. Antithrombotic Trialists' Collaboration. Collaborative meta-analysis of randomised trials of antiplatelet therapy for prevention of death, myocardial infarction, and stroke in high risk patients. BMJ. 2002; 324(7329): 71-86, doi: 10.1136/bmj.324.7329.71, indexed in Pubmed: 11786451.

21. Kubica A, Kasprzak M, Siller-Matula J, et al. Time-related changes in determinants of antiplatelet effect of clopidogrel in patients after myocardial infarction. Eur J Pharmacol. 2014; 742: 47-54, doi: 10.1016/j.ejphar.2014.08.009, indexed in Pubmed: 25199965.

22. Serebruany VL, Midei MG, Meilman H, et al. Platelet inhibition with prasugrel (CS-747) compared with clopidogrel in patients undergoing coronary stenting: the subset from the JUMBO study. Postgrad Med J. 2006; 82(968): 404-410, doi: 10.1136/pgmj.2006.047696, indexed in Pubmed: 16754711 .

23. Wiviott SD, Trenk D, Frelinger AL, et al. PRINCIPLE-TIMI 44 Investigators. Prasugrel compared with high loading- and maintenance-dose clopidogrel in patients with planned percutaneous coronary intervention: the Prasugrel in Comparison to Clopidogrel for Inhibition of Platelet Activation and Aggregation-Thrombolysis in Myocardial Infarction 44 trial. Circulation. 2007; 116(25): 2923-2932, doi: 10.1161/CIRCULATIONAHA.107.740324, indexed in Pubmed: 18056526.

24. Husted SE, Storey RF, Bliden K, et al. Pharmacokinetics and pharmacodynamics of ticagrelor in patients with stable coronary artery disease: results from the ONSET-OFFSET and RESPOND studies. Clin Pharmacokinet. 2012; 51(6): 397-409, doi: 10.2165/11599830-000000000-00000, indexed in Pubmed: 22515556.

25. Storey R, Husted S, Harrington R, et al. Inhibition of platelet aggregation by AZD6140, a reversible oral P2Y12 receptor antagonist, compared with clopidogrel in patients with acute coronary syndromes. J Am Coll Cardiol. 2007; 50(19): 1852-1856, doi: 10.1016/j.jacc.2007.07.058.

26. Wiviott SD, Braunwald E, McCabe CH, et al. TRITON-TIMI 38 Investigators. Prasugrel versus clopidogrel in patients with acute coronary syndromes. N Engl J Med. 2007; 357(20): 2001-2015, doi: 10.1056/NEJMoa0706482, indexed in Pubmed: 17982182

27. Wiviott SD, Braunwald E, Angiolillo DJ, et al. TRITON-TIMI 38 Investigators. Greater clinical benefit of more intensive oral antiplatelet therapy with prasugrel in patients with diabetes mellitus in the trial to assess improvement in therapeutic outcomes by optimizing platelet inhibition with prasugrel-Thrombolysis in Myocardial Infarction 38. Circulation. 2008; 118(16): 1626-1636, doi: 10.1161/CIRCULATIONAHA.108.791061, indexed in Pubmed: 18757948.

28. Wallentin L, Becker RC, Budaj A, et al. PLATO Investigators. Ticagrelor versus clopidogrel in patients with acute coronary syndromes. NEngl J Med. 2009; 361(11): 1045-1057, doi: 10.1056/NEJMoa0904327, indexed in Pubmed: 19717846.

29. Adamski P, Adamska U, Ostrowska M, et al. New directions for pharmacotherapy in the treatment of acute coronary syndrome. Expert Opin Pharmacother. 2016; 17(17): 2291-2306, doi: 10.1080/14656566.2016.1241234, indexed in Pubmed: 27677394.

30. Kubica J, Kozinski M, Navarese EP, et al. Cangrelor: an emerging therapeutic option for patients with coronary artery disease. Curr Med Res Opin. 2014; 30(5): 813-828, doi: 10.1 185/03007995.2014.880050, indexed in Pubmed: 24393016.
31. Bhatt D, Stone G, Mahaffey K, et al. Effect of platelet inhibition with cangrelor during PCI on ischemic events. N Engl J Med. 2013; 368(14): 1303-1313, doi: 10.1056/nejmoa1300815.

32. Kubica J, Pstragowski K, Adamski P, et al. Mild therapeutic hypothermia for patients with acute coronary syndrome and cardiac arrest treated with percutaneous coronary intervention (UNICORN). The design and rationale for the prospective, observational, multicenter study. Med Res J. 2016; 1(1): 23-27, doi: 10.5603/mrj.2016.0004.

33. Klimczuk T, Kubica J, Kasprzak M, et al. Łagodna hipotermia terapeutyczna po nagłym zatrzymaniu krążenia w przebiegu ostrego zespołu wieńcowego - doświadczenia z wdrażania metody. Folia Cardiol. 2015; 10(1): 19-24, doi: 10.5603/FC.2015.0005.

34. Parodi G. Editor's Choice-Chest pain relief in patients with acute myocardial infarction. Eur Heart J Acute Cardiovasc Care. 2016; 5(3): 277-281, doi: 10.1177/2048872615584078, indexed in Pubmed: 25904757.

35. Kubica J, Kubica A, Jilma B, et al. Impact of morphine on antiplatelet effects of oral P2Y12 receptor inhibitors. Int JCardiol. 2016; 215: 201-208, doi: 10.1016/j.ijcard.2016.04.077, indexed in Pubmed: 27128531.

36. Therapy guide - Naloxonum hydrochloricum WZF.

37. Puymirat E, Lamhaut L, Bonnet N, et al. Correlates of pre-hospital morphine use in ST-elevation myocardial infarction patients and its association with in-hospital outcomes and long-term mortality: the FAST-MI (French Registry of Acute ST-elevation and non-ST-elevation Myocardial Infarction) programme. Eur Heart J. 2016; 37(13): 1063-1071, doi: 10.1093/eurheartj/ehv567, indexed in Pubmed: 26578201.

38. Meine TJ, Roe MT, Chen AY, et al. CRUSADE Investigators. Association of intravenous morphine use and outcomes in acute coronary syndromes: results from the CRUSADE Quality Improvement Initiative. Am Heart J. 2005; 149(6): 1043-1049, doi: 10.1016/j.ahj.2005.02.010, indexed in Pubmed: 15976786.

39. Iakobishvili Z, Porter A, Battler A, et al. Effect of narcotic treatment on outcomes of acute coronary syndromes. Am J Cardiol. 2010; 105(7): 912-916, doi: 10.1016/j.amjcard.2009.11.027, indexed in Pubmed: 20346305.

40. Parodi G, Valenti R, Bellandi B, et al. Comparison of prasugrel and ticagrelor loading doses in ST-segment elevation myocardial infarction patients: RAPID (Rapid Activity of Platelet Inhibitor Drugs) primary PCI study. J Am Coll Cardiol. 2013; 61(15): 1601-1606, doi: 10.1016/j.jacc.2013.01.024, indexed in Pubmed: 23500251.

41. de Waha S, Eitel I, Desch S, et al. Intravenous morphine administration and reperfusion success in ST-elevation myocardial infarction: insights from cardiac magnetic resonance imaging. Clin Res Cardiol. 2015; 104(9): 727-734, doi: 10.1007/s00392015-0835-2, indexed in Pubmed: 25725777.

42. Hobl EL, Stimpfl T, Ebner J, et al. Morphine decreases clopidogrel concentrations and effects: a randomized, doubleblind, placebo-controlled trial. J Am Coll Cardiol. 2014; 63(7): 630-635, doi: 10.1016/j.jacc.2013.10.068, indexed in Pubmed: 24315907.

43. Parodi G, Bellandi B, Xanthopoulou I, et al. Morphine is associated with a delayed activity of oral antiplatelet agents in patients with ST-elevation acute myocardial infarction undergoing primary percutaneous coronary intervention. Circ Cardiovasc Interv. 2015; 8(1), doi: 10.1161/CIRCINTERVENTIONS.114.001593, indexed in Pubmed: 25552565.

44. Kubica J, Adamski P, Ostrowska M, et al. Influence of Morphine on Pharmacokinetics and Pharmacodynamics of Ticagrelor in Patients with Acute Myocardial Infarction (IMPRESSION): study protocol for a randomized controlled trial. 
Trials. 2015; 16: 198-252, doi: 10.1186/s13063-015-0724-z, indexed in Pubmed: 25925591.

45. Kubica J, Adamski P, Ostrowska M, et al. Morphine delays and attenuates ticagrelor exposure and action in patients with myocardial infarction: the randomized, double-blind, placebo-controlled IMPRESSION trial. Eur Heart J. 2016; 37(3): 245-252, doi: 10.1093/eurheartj/ehv547, indexed in Pubmed: 26491112 .

46. Iakobishvili Z, Cohen E, Garty M, et al. Heart Failure Survey in Isarel (HFSIS) Investigators. Use of intravenous morphine for acute decompensated heart failure in patients with and without acute coronary syndromes. Acute Card Care. 2011; 13(2): 76-80, doi: 10.3109/17482941.2011.575165, indexed in Pubmed: 21627393.

47. Held C, Asenblad N, Bassand JP, et al. Ticagrelor versus clopidogrel in patients with acute coronary syndromes undergoing coronary artery bypass surgery: results from the PLATO (Platelet Inhibition and Patient Outcomes) trial. J Am Coll Cardiol. 2011; 57(6): 672-684, doi: 10.1016/j.jacc.2010.10.029, indexed in Pubmed: 21194870.

48. Roe MT, Armstrong PW, Fox KAA, et al. TRILOGY ACS Investigators. Prasugrel versus clopidogrel for acute coronary syndromes without revascularization. N Engl J Med. 2012; 367(14): 1297-1309, doi: 10.1056/NEJMoa1205512, indexed in Pubmed: 22920930.

49. Montalescot G, Bolognese L, Dudek D, et al. ACCOAST Investigators. Pretreatment with prasugrel in non-ST-segment elevation acute coronary syndromes. N Engl J Med. 2013; 369(11): 999-1010, doi: 10.1056/NEJMoa1308075, indexed in Pubmed: 23991622.

50. Sibbing D, Kastrati A, Berger PB. Pre-treatment with P2Y12 inhibitors in ACS patients: who, when, why, and which agent? Eur Heart J. 2016; 37(16): 1284-1295, doi: 10.1093/eurheartj/ehv717, indexed in Pubmed: 26712838.

51. Montalescot G, van 't Hof AW, Lapostolle F, et al. ATLANTIC Investigators. Prehospital ticagrelor in ST-segment elevation myocardial infarction. NEngl J Med. 2014; 371(11): 1016-1027, doi: 10.1056/NEJMoa1407024, indexed in Pubmed: 25175921.

52. Montalescot G, van 't Hof AW, Bolognese L, et al. ATLANTIC Investigators. Effect of Pre-Hospital Ticagrelor During the First
$24 \mathrm{~h}$ After Primary Percutaneous Coronary Intervention in Patients With ST-Segment Elevation Myocardial Infarction: The ATLANTIC- $\mathrm{H}^{24}$ Analysis. JACC Cardiovasc Interv. 2016; 9(7): 646-656, doi: 10.1016/j.jcin.2015.12.024, indexed in Pubmed: 26952907.

53. Kleinrok A, Płaczkiewicz DT, Puźniak M, et al. Electrocardiogram teletransmission and teleconsultation: essential elements of the organisation of medical care for patients with ST segment elevation myocardial infarction: a single centre experience. Kardiol Pol. 2014; 72(4): 345-354, doi: 10.5603/KP.a2013.0352, indexed in Pubmed: 24408066.

54. Directive of the Minister of Health dated 20 April 2016 on medical rescue procedures and health services different than medical rescue procedures, which can be performed by paramedic.

55. Abraham NS, Hlatky MA, Antman EM, et al. ACCF/ACG/AHA. ACCF/ACG/AHA 2010 expert consensus document on the concomitant use of proton pump inhibitors and thienopyridines: a focused update of the ACCF/ACG/AHA 2008 expert consensus document on reducing the gastrointestinal risks of antiplatelet therapy and NSAID use. A Report of the American College of Cardiology Foundation Task Force on Expert Consensus Documents. J Am Coll Cardiol. 2010; 56(24): 2051-2066, doi: 10.1016/j.jacc.2010.09.010, indexed in Pubmed: 21126648.

56. Alexopoulos D, Barampoutis N, Gkizas V, et al. Crushed Versus Integral Tablets of Ticagrelor in ST-Segment Elevation Myocardial Infarction Patients: A Randomized Pharmacokinetic/Pharmacodynamic Study. Clin Pharmacokinet. 2016; 55(3): 359-367, doi: 10.1007/s40262-015-0320-0, indexed in Pubmed: 26315810.

57. Parodi G, Xanthopoulou I, Bellandi B, et al. Ticagrelor crushed tablets administration in STEMI patients: the MOJITO study. J Am Coll Cardiol. 2015; 65(5): 511-512, doi: 10.1016/j. jacc.2014.08.056, indexed in Pubmed: 25660931.

58. Rollini F, Franchi F, Hu J, et al. Crushed prasugrel tablets in patients with STEMI undergoing primary percutaneous coronary intervention. J Am Coll Cardiol. 2016; 67(17): 1994-2004, doi: 10.1016/j.jacc.2016.02.045.

Cite this article as: Kubica J, Adamski P, Paciorek P, et al. Anti-aggregation therapy in patients with acute coronary syndrome recommendations for medical emergency teams. Experts' standpoint. Kardiol Pol. 2017; 75(4): 399-408, doi: 10.5603/KP.a2017.0057. 